\title{
Recombinant Newcastle disease virus (NDV) with inserted gene coding for GM-CSF as a new vector for cancer immunogene therapy
}

\author{
M Janke ${ }^{1,4}$, B Peeters ${ }^{2}$, O de Leeuw ${ }^{3}$, R Moorman ${ }^{3}$, A Arnold ${ }^{1}$, P Fournier ${ }^{1}$ and V Schirrmacher ${ }^{1}$ \\ ${ }^{1}$ Division of Cellular Immunology, German Cancer Research Center, Im Neuenheimer Feld 280, Heidelberg, Germany; ${ }^{2}$ Division of \\ Virology, Central Institute for Animal Disease Control Lelystad (CIDC-Lelystad), Lelystad, The Netherlands; ${ }^{3}$ Division of Infectious \\ Diseases, Animal Sciences Group, Wageningen University and Research Centre, Lelystad, The Netherlands and ${ }^{4}$ Division of Clinical \\ Pharmacology, University Hospital, University of Bonn, Sigmund-Freud-Street 25, Bonn, Germany
}

This is the first report describing recombinant (rec) Newcastle disease virus (NDV) as vector for gene therapy of cancer. The gene encoding granulocyte/macrophage colony-stimulating factor (GM-CSF) was inserted as an additional transcription unit at two different positions into the NDV genome. The rec virus with the strongest production of the gene product (rec(GM-CSF)) was selected for our study. The insertion of the new foreign gene did neither affect the main features of NDV replication nor its tumor selectivity. The gene product was biologically active and stable. Tumor vaccine cells infected by rec(GM-CSF) stimulated human peripheral blood mononuclear cells (PBMC) to exert antitumor bystander effects in vitro in a tumor neutralization assay. These effects were significantly increased when compared to vaccine infected by rec(-) virus. Furthermore, rec(GM-CSF) led to a much higher interferon- $\alpha$ (IFN- $\alpha$ ) production than rec(-) when added as virus or as virus-modified vaccine to PBMC. Two distinct cell types, monocytes and plasmacytoid dendritic cells were shown to contribute to the augmented IFN- $\alpha$ response of PBMC. In conclusion, the already inherent anti-neoplastic and immunostimulatory properties of NDV could be further augmented by the introduction of a therapeutic gene whose product initiates a broad cascade of immunological effects in the microenvironment of the vaccine.

Gene Therapy (2007) 14, 1639-1649; doi:10.1038/

sj.gt.3303026; published online 4 October 2007

Keywords: Newcastle disease virus; granulocyte/macrophage colony-stimulating factor; tumor therapy; vaccine

\section{Introduction}

Newcastle disease virus (NDV) is used to treat human cancer either in the form of free virus ${ }^{1}$ or in the form of virus-infected tumor cell vaccine. ${ }^{2}$ Three cellular mechanisms have been proposed for its anti-neoplastic activities: (i) oncolysis: ${ }^{3}$ oncolytic strains may simply kill tumor cells directly. (ii) Provision of danger signals: $:^{4,5}$ replication of NDV occurs in the tumor cells' cytoplasm. It is associated with the production of single- and doublestranded viral RNA. NDV infection of tumor cells thus introduces danger signals ${ }^{6}$ that can be recognized by RIG$\mathrm{I}^{7}$ and $\mathrm{PKR}^{8}$ in the cytoplasm and by Toll-like receptors ${ }^{9}$ in endosomes. (iii) Immune cell activation: application of NDV may stimulate the host to produce cytokines such as interferons (IFNs) or tumor necrosis factor (TNF), which in turn leads to the activation of natural killer (NK) cells, monocytes, macrophages and sensitized $\mathrm{T}$ cells.

In our laboratory, we have established a tumor vaccine, which consists of irradiated autologous tumor cells, infected with the non-lytic NDV strain Ulster.

Correspondence: Professor V Schirrmacher, Division of Cellular Immunology, German Cancer Research Center (DKFZ), Im Neuenheimer feld 280, Heidelberg D-69120, Germany.

E-mail: V.Schirrmacher@dkfz-heidelberg.de

Received 11 April 2007; revised 29 July 2007; accepted 30 July 2007; published online 4 October 2007
Already in 1986, we first reported on successful postoperative active-specific immunotherapy (ASI) with virus modified-but not with unmodified-murine ESb lymphoma cells, which caused protection from metastases in about 50\% of syngenic mice. ${ }^{10}$ Protective antitumor immunity in the ESb lymphoma model was highly specific for the autologous tumor line. ${ }^{11}$

On the basis of these preclinical observations, we subsequently established a similar autologous NDV virus-modified tumor vaccine (ATV-NDV) for human application. ${ }^{2,12}$ Recently, we reported results from two non-randomized phase II studies, which aimed at feasibility, safety and clinical benefit. In both studies (glioblastoma multiforme (GBM) ${ }^{13}$ and head and neck carcinoma (HNSCC) ${ }^{14}$ ), the establishment of primary tumor cell cultures was feasible and successful in about 80-90\%. All tumor cells tested could be successfully infected by NDV and showed cell surface expression of MHC I and viral HN molecules. Clinical benefits in GBM included one complete remission and prolongation of median overall-survival (100 weeks versus 49 weeks in controls $\left.{ }^{13}\right)$. Clinical benefits in the HNSCC study included improvement of the 5-year survival rate in stage III and IV (61 versus 38\%). ${ }^{14}$

In recent years, reverse genetics technology enabled to generate recombinant strains from non-segmented negative strand RNA viruses. Such techniques allowed 
recovering recombinant NDV entirely from cloned cDNA of the non-lytic strain La Sota. ${ }^{15}$

The aim of this study was to optimize a tumor vaccine by increasing the induced anti-tumor immunity. Recombinant (rec) NDV strains with an inserted therapeutic gene encoding either human or murine GM-CSF were thus produced. We will demonstrate a significant augmentation of anti-tumor activity upon stimulation of human peripheral blood mononuclear cells (PBMCs) from healthy donors with tumor vaccine infected with rec(GM-CSF) in comparison to a vaccine infected with recombinant NDV without a foreign gene $(\operatorname{rec}(-))$.

We observed activation of innate immune cells such as monocytes and dendritic cells (DCs) by tumor vaccine infected with the rec(GM-CSF) when compared to vaccine infected with $\operatorname{rec}(-)$. We will show that rec(GM-CSF) vaccine leads to an enhanced IFN- $\alpha$ production by PBMC, which is due to the activity of monocytes and plasmacytoid DCs (PDCs).

In conclusion, our results provide the proof of principle that an incorporated therapeutic gene further augments the immunostimulatory and anti-neoplastic properties of NDV. This opens new possibilities for further optimization of the ATV-NDV tumor vaccine ${ }^{13,14,16}$ and for systemic application of recombinant NDV with incorporated therapeutic genes.

\section{Results}

\section{Production of recombinant NDV viruses with the GM-CSF gene}

Two new recombinant (rec) NDV strains each containing the human GM-CSF gene incorporated at different positions within the viral genome (in front of the NP gene and between the $\mathrm{HN}$ and $\mathrm{L}$ gene, see Figure 1a) were generated by reverse genetics. We also generated a rec virus with a murine GM-CSF gene in front of the NP gene. The genes were cloned into the plasmid pNDFL $+{ }^{15}$ which contains the viral genome of NDV. A DNA fragment containing the gene encoding human or murine GM-CSF was obtained by means of PCR using the plasmid pCD-hGM-CSF as template. It was then inserted into plasmid pNDFL+ between the transcriptionstart box of the NP gene and the NP open reading frame. ${ }^{15}$ In order to allow transcription of downstream genes, a synthetic nucleotide sequence corresponding to the consensus transcription-end box and transcriptionstart box (ATTAAGAAAAAATACGGGTAGAAG) of NDV was inserted behind the therapeutic gene. The resulting plasmid was used to rescue recombinant NDV as described previously. ${ }^{15}$ The rescued virus was designated rec(GM-CSF) or rec(mGM-CSF) respectively. The hGM-CSF gene was also inserted between the HN and $\mathrm{L}$ gene of NDV by replacing the SEAP gene in plasmid $\mathrm{pHZ}-\mathrm{SEAP} / \mathrm{HN}-\mathrm{L}^{17}$ and by rescuing the virus referred here as rec(GM-CSF (II)). All rec NDV strains could be grown to high titers in the allantoic fluid of embryonated chicken eggs.

\section{Production of GM-CSF and biological activity}

As shown in Figure 1b, human MCF-7 breast carcinoma cells infected with rec(GM-CSF) produced five times more gene product in comparison to rec(GM-CSF (II)). No GM-CSF protein could be detected in the supernatant a

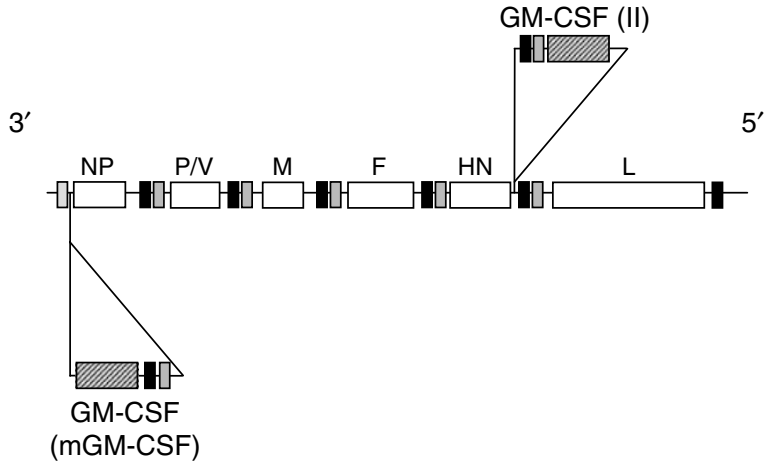

b

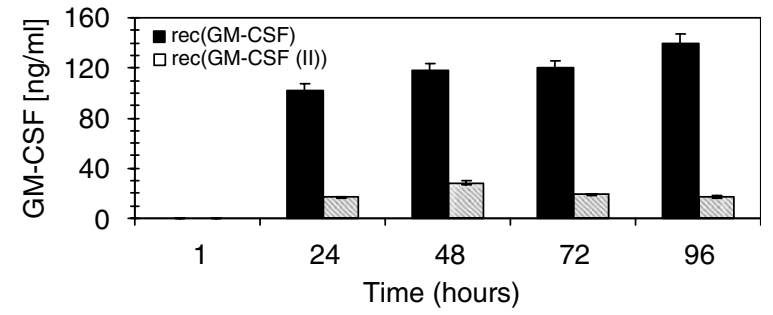

Figure 1 Comparison of the recombinant NDV with the GM-CSF gene inserted at two different positions. (a) Insertion sites of the therapeutic GM-CSF gene within the NDV minigenome. In the first construct, the GM-CSF gene was inserted in front of the NP gene (position I). In this case, a GE sequence followed by a GS sequence were added between the inserted gene and the viral NP gene. The position II corresponds to the insertion of the GM-CSF gene between the HN and the L gene. Here, a GE and a GS box were inserted between the $\mathrm{HN}$ and the inserted GM-CSF gene. Black boxes indicate conserved gene-end (GE) sequences. Shaded boxes indicate conserved gene-start (GS) sequences. (b) Position effect of the GM-CSF gene within the viral genome on its expression. MCF-7 cells were infected with rec(GM-CSF) or rec(GM-CSF (II)) as described in Materials and Methods ( $100 \mathrm{HU}$ per $10^{7}$ cells per ml). The cells $\left(1.2 \times 10^{5}\right.$ cells $\left.\mathrm{ml}^{-1}\right)$ were left in culture for up to 4 days and the amount of the GM-CSF protein in the supernatants of these cultures was analyzed by ELISA. GM-CSF, granulocyte/macrophage colony-stimulating factor; NDV, Newcastle disease virus.

of tumor cells infected with rec(-) virus (data not shown). Thus, the integration site of the therapeutic gene within the viral genome has a strong influence on the level of the protein expressed. The supernatants had the capacity to stimulate the growth of the GM-CSFdependent cell line TF-1 in a linear dose-dependent manner (Figure 2a).

To test for biological activity, we added supernatants from murine ESb tumor cells infected by rec(mGM-CSF) or rec(-) virus to murine bone marrow derived cells and evaluated the generation of CD11c-positive DCs after 10 days of cultivation. As shown in Figure 2b, the supernatant from rec(mGM-CSF)-infected tumor cells caused a similar expansion of bone marrow cell numbers and maturation of DCs as the positive control, a supernatant from Ag8653 tumor cells producing mGM-CSF.

We conclude that the production of rec NDV viruses with incorporated human or murine genes is feasible and that the viruses produce a gene product with biological activity.

\section{Main characteristics of rec(GM-CSF) virus}

For tumor vaccine production it is important to know tumor cell-binding properties, virus replication behavior 


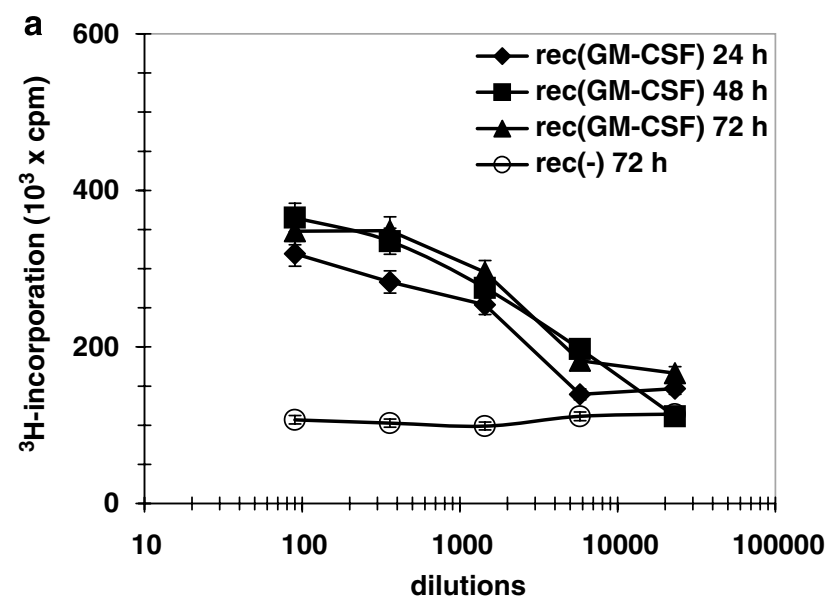

b

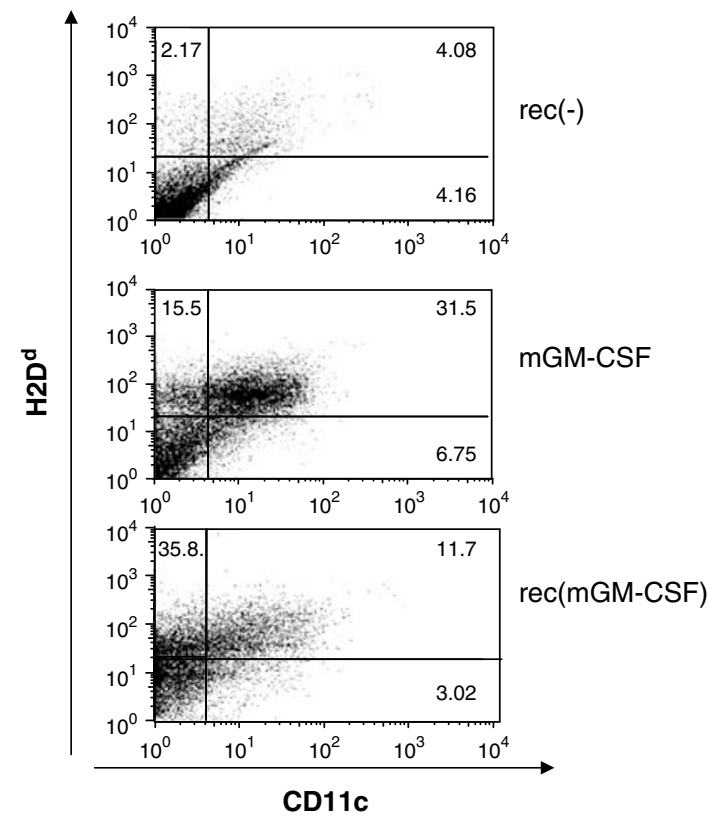

Figure 2 Biological activity of the produced GM-CSF protein inserted in the recombinant virus. (a) Human GM-CSF: TF-1 assays of supernatants of cells infected with rec(GM-CSF). MCF-7 cells were infected with $\mathrm{rec}(-)$ or $\mathrm{rec}(\mathrm{GM}-\mathrm{CSF})$, cultured at $1.4 \times 10^{5}$ cells $\mathrm{ml}^{-1}$ and the supernatants of these cultures were taken after 24 , 48 and $72 \mathrm{~h}$. They were then added in serial dilutions to GM-CSFsensitive TF- 1 cells and incubated for $72 \mathrm{~h}$. The proliferation of the TF-1 cells was determined by measuring uptake of radioactive ${ }^{3} \mathrm{H}$-labeled thymidine during $4 \mathrm{~h}$ of pulse. (b) Murine GM-CSF: expansion of murine bone marrow-derived cells with supernatants of cells infected with rec(mGM-CSF). A total of $2 \times 10^{6}$ freshly prepared bone marrow cells from $\mathrm{DBA} / 2\left(\mathrm{H}-2 \mathrm{D}^{\mathrm{d}}\right)$ mice were distributed in four different groups in $10 \mathrm{~cm}$ Petri dishes. Then X-Vivo20 medium supplemented with $20 \% \mathrm{v} / \mathrm{v}$ of supernatant from ESb-LCI cells infected with rec(-) for $72 \mathrm{~h}\left(5 \times 10^{5}\right.$ cells ml-1; top), of supernatant from Ag8653 cells that produce mouse GM-CSF (positive control, middle) or of supernatants from ESb-LCI cells

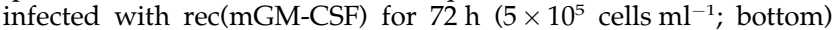
was added. The fourth group corresponding flow cytometry to X-Vivo20 medium without any supplement showed the same FACS profile as the first flow cytometry group (top). The medium was changed every 3 days. On day 10, the cells were labeled with FITClabeled anti-mouse CD11c antibody and PE-labeled anti-H2D ${ }^{d}$ antibody (both diluted 1:100) before being analyzed by flow cytometry. FITC, fluorescein isothiocyanate; GM-CSF, granulocyte/macrophage colony-stimulating factor and cytotoxic effects. Therefore, we investigated these aspects for the strains $\operatorname{rec}(-)$ and $\operatorname{rec}(\mathrm{GM}-\mathrm{CSF})$ and compared them with NDV strain Ulster. As target cells we used the human breast carcinoma line MCF-7 (Figures $3 \mathrm{a}$ and $\mathrm{b}$ ), the human breast hyperplasiaderived epithelial cell line MCF-10A, the colon-carcinoma line HT29 and the T-cell lymphoma line Jurkat. The rec virus strains derived from lentogenic NDV La Sota behaved in all cell lines similar to the lentogenic NDV Ulster. Viral replication in the cytoplasm was associated with an increase of the density of cell surface-expressed viral $\mathrm{HN}$ and $\mathrm{F}$ proteins. The rec strains were also similar to NDV Ulster in that they were not able to replicate in normal human cells and that supernatants from infected tumor cells were non-infectious due to an uncleaved Fprotein in the newly synthesized virion particles (data not shown).

We also compared the rec strains and wild-type NDV Ulster with regard to their capacity to induce late apoptotic events in MCF-7 breast carcinoma cells (Figure 3c). The recombinant viruses were about three times more effective in inducing cytotoxicity in the tumor cells than NDV Ulster. Only a small difference was seen between rec(-) and rec(GM-CSF) viruses.

\section{Expression and stability of the therapeutic gene product}

We infected the above four cell lines and tested their supernatants by enzyme-linked immunosorbent assay (ELISA) for content of GM-CSF after $48 \mathrm{~h}$ of in vitro culture. Rec(GM-CSF) expressed its gene product in all four tumor cell lines tested. The highest expression was found in MCF-7 cells (Figure 4; $128 \mathrm{ng}$ GM-CSF ml ${ }^{-1}$ ). These were followed by MCF-10A and Jurkat cells, while the lowest expression was seen in HT29 cells, which produced only $34 \mathrm{ng}$ GM-CSF ml ${ }^{-1}$.

We then studied the kinetics of cytokine production and also the effect of $\gamma$-irradiation of the infected cells on their capacity to produce cytokine. Figure 4a shows that $\gamma$-irradiation had only a small effect on GM-CSF production. Maximum levels of cytokine expression were seen after $48 \mathrm{~h}$ of cell culture.

We then evaluated the expression of the therapeutic gene product in dependence on the number of irradiated MCF-7 vaccine cells added per well of a 96-well plate. While 750 cells produced only $12 \mathrm{ng} \mathrm{ml}^{-1}$ cytokine, 96000 cells produced $390 \mathrm{ng} \mathrm{ml}^{-1}$ GM-CSF (Figure 4b).

Of further importance was the question of stability. Supernatants taken 1, 2, 3 or 4 days after infection were centrifuged and stored at $-20{ }^{\circ} \mathrm{C}, 4{ }^{\circ} \mathrm{C}$ or incubated at $37^{\circ} \mathrm{C}$ for 30 days before analyzing the specific protein content by ELISA. The results (Table 1) show that GMCSF was stable for 30 days at body temperature.

\section{Effect of GM-CSF-producing tumor vaccine in a tumor neutralization assay}

This functional assay is basically a mixed lymphocytetumor vaccine culture (MLTC) run on top of a tumor cell monolayer. It enables to test human PBMC-mediated bystander antitumor, cytotoxic or cytostatic effects on the tumor monolayer. While we previously performed the tumor neutralization assay (TNA) in 96-well plates with 750 vaccine cells, ${ }^{18}$ we had to increase the vaccine cell number to have enough of the therapeutic gene product 

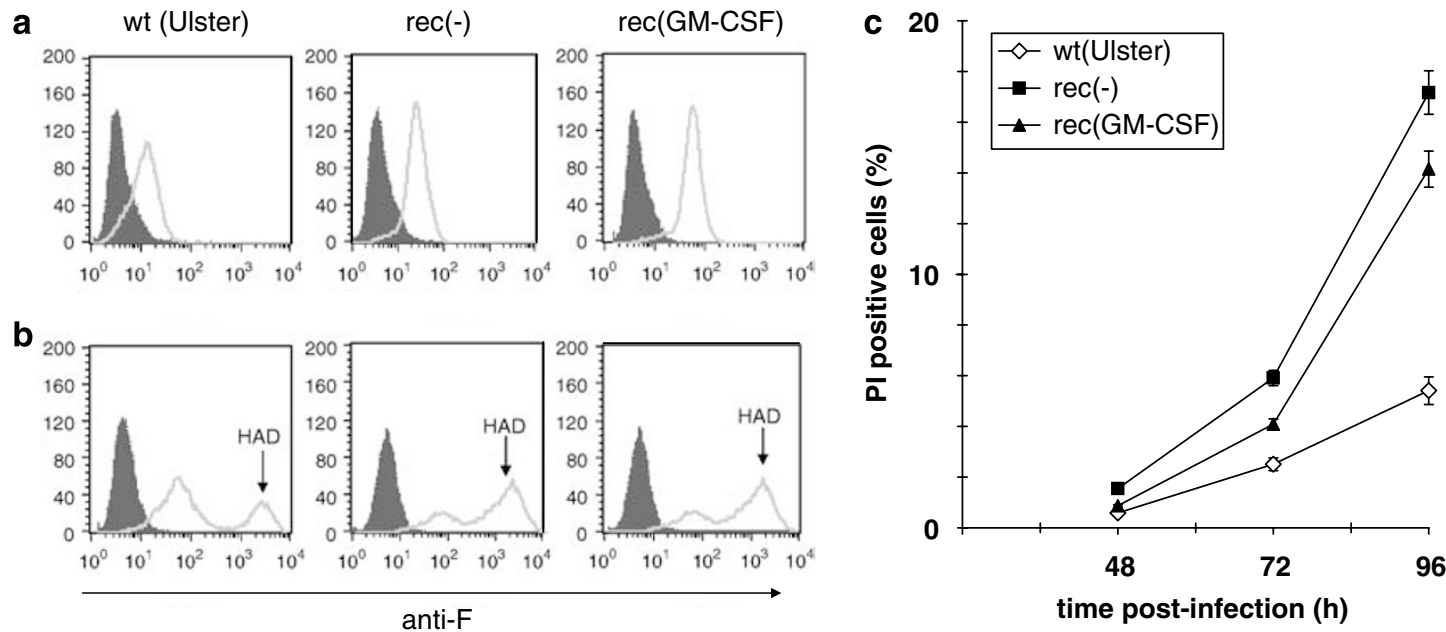

Figure 3 Tumor cell binding, virus replication and proapoptotic activity of the recombinant NDV strains. Virus binding (a) and replication (b) $1 \times 10^{7}$ MCF-7 cells were incubated in $1 \mathrm{ml}$ volume with $100 \mathrm{HU}$ of the indicated NDV strains for $1 \mathrm{~h}$ at $37^{\circ} \mathrm{C}$ and then washed. In (a) the cells were directly stained for expression of viral antigens whereas in (b) they were further incubated for $24 \mathrm{~h}$ to allow for virus replication before the cells were stained. Staining was performed with mouse anti-F mAb ( $1 \mu \mathrm{g} / 5 \times 10^{5}$ cells) followed by PE-labeled goat anti-mouse Ig secondary antibody (1:50). The dark profiles show staining controls with secondary antibody only. The white histograms show the expression of viral F protein. Notice that without viral replication there is only F-expression at low antigen density whereas after infection and replication the tumor cells show a distinct population of cells with F-expression at high antigen density (HAD). (c) Assessment of apoptosis by Nicoletti staining. Apoptosis induction in $5 \times 10^{5}$ MCF-7 cells per sample was measured by Nicoletti staining 48,72 and $96 \mathrm{~h}$ after infection with the different NDV viruses (wt(Ulster), rec(-) and rec(GM-CSF) (same conditions of infection as in a). The percentage of propidium iodide-positive cells was calculated at each time point. NDV, Newcastle disease virus; GM-CSF, granulocyte/macrophage colony-stimulating factor.
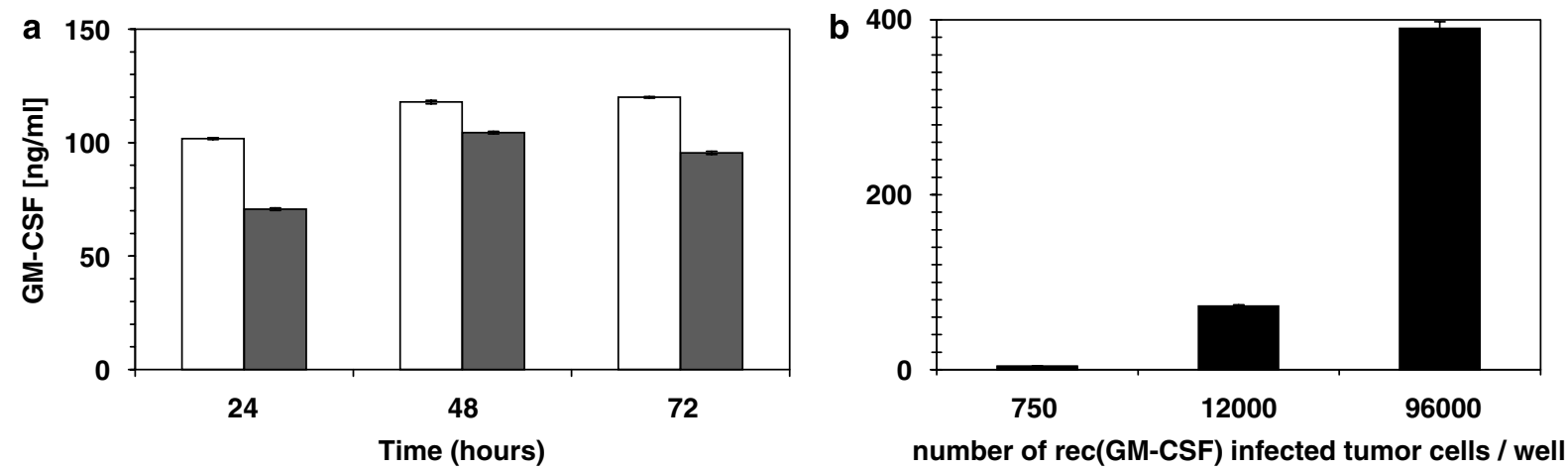

Figure 4 Expression of the therapeutic gene product in tumor cells after infection with rec NDV. (a) Kinetics of the expression of the therapeutic gene product. MCF-7 tumor cells were infected with rec(GM-CSF) and cultured as described for Figure 1b. The experiment was performed with non-irradiated (white bars) or irradiated (black bars) MCF-7 tumor cells as for vaccine production. At different times (24, 48 and $72 \mathrm{~h}$ ) after NDV infection, the cultured supernatants were tested for content of the therapeutic gene product by ELISA. rec(-)-infected control cultures did not produce GM-CSF (data not shown). (b) Dependence of the number of irradiated and infected MCF-7 vaccine cells on the expression of the therapeutic gene. After infection with rec(GM-CSF), MCF-7 cells were seeded at different numbers per well (750, 12 000 and 96000 per $200 \mu \mathrm{l}$ ) in a 96-well plate. The expression of the therapeutic gene product was analyzed $48 \mathrm{~h}$ later by ELISA. The columns show means and standard deviations from triplicates. NDV, Newcastle disease virus; ELISA, enzyme-linked immunosorbent assay; GM-CSF, granulocyte/macrophage colony-stimulating factor.

produced during the assay. An optimized test was thus established in 48-well plates containing 24000 vaccine cells (V) and 96000 PBMC as responder cells.

After 5-6 days of culture, the amount of live tumor cells was measured by uptake of the vital dye 3-(4, 5-dimethylthiazol-2-yl)-5-(3 carboxymethoxyphenyl)-2(4-sulfophenyl)-2H-tetrazolium, inner salt (MTS) and the produced brown color was quantified in an ELISA reader at $490 \mathrm{~nm}$.

These assays were performed with PBMC from 14 different healthy donors because of individual variability in activity. While in absence of virus infection the vaccine cells (V) did not induce tumor growth inhibition (TGI) (see Figure 5), we observed about 30\% TGI when virusmodified vaccine cells (VN) were added on top of the tumor cell monolayer. Upon addition of PBMC we saw a further increase of TGI up to $80 \%$, while PBMC without vaccine cells had no growth inhibitory effect. The results are summarized in Figure 5. The highest mean of $82.3 \%$ TGI was obtained with rec(GM-CSF) in presence of PBMC. This was significantly higher than the effect seen with rec(-) and PBMC and thus provides the proof of principle of an added value of the incorporated gene for the tumor vaccine. 


\section{Effect of the recombinant viruses on the IFN- $\alpha$} response of $P B M C$

To elucidate mechanisms, which could explain the observed higher antitumor activity when using

Table 1 Stability of the expressed GM-CSF protein

\begin{tabular}{|c|c|c|}
\hline $\begin{array}{l}\text { Supernatants } \\
\text { (hours after } \\
\text { infection) }\end{array}$ & $\begin{array}{c}\text { Incubation time: } 30 \text { days } \\
\text { incubation temperature } \\
\left({ }^{\circ} \mathrm{C}\right)\end{array}$ & $\begin{array}{l}\text { Recovered GM-CSF } \\
\text { concentration } n g / m l \\
\text { (\%) }\end{array}$ \\
\hline 24 & $\begin{array}{r}-20 \\
4 \\
37\end{array}$ & $\begin{array}{c}101.8(100) \\
109.9(108) \\
96.4(95)\end{array}$ \\
\hline 48 & $\begin{array}{r}-20 \\
4 \\
37\end{array}$ & $\begin{array}{l}117.9(100) \\
120.9(103) \\
117.2(99)\end{array}$ \\
\hline 72 & $\begin{array}{r}-20 \\
4 \\
37\end{array}$ & $\begin{array}{l}120.0(100) \\
121.9(102) \\
117.9(98)\end{array}$ \\
\hline 96 & $\begin{array}{r}-20 \\
4 \\
37\end{array}$ & $\begin{array}{l}140.0(100) \\
128.6(92) \\
127.1(91)\end{array}$ \\
\hline
\end{tabular}

GM-CSF, granulocyte/macrophage colony-stimulating factor; ELISA, enzyme-linked immunosorbent assay.

MCF-7 cells were infected with rec(GM-CSF) $\left(100 \mathrm{HU}\right.$ per $10^{7}$ cells per $\mathrm{ml}$ ) and cultured as described for Figure 1b. After culture for 24, 48,72 and $96 \mathrm{~h}$, the supernatants were collected and stored at three different temperatures $\left(-20,4\right.$ and $\left.37^{\circ} \mathrm{C}\right)$ for 30 days. All samples were simultaneously analyzed for GM-CSF by ELISA. Numbers in brackets represent the percentage of GM-CSF concentration determined after storage at 4 or $37^{\circ} \mathrm{C}$ taking as reference the sample stored at $-20^{\circ} \mathrm{C}$.
rec(GM-CSF) instead of $\mathrm{rec}(-)$-infected tumor vaccine, we analyzed the supernatants of the TNA for the expression of a panel of cytokines. These tests revealed that the amount of IFN- $\alpha$ was significantly higher in the TNA assays performed with rec(GM-CSF) than those with $\operatorname{rec}(-)$. When the TNA was performed with human purified $\mathrm{T}$ cells instead of PBMC as effector cells, no increase of IFN- $\alpha$ was seen (data not shown).

We next tested the IFN- $\alpha$ response of PBMC after coincubation with increasing amounts of either rec(-) or rec(GM-CSF). The results obtained with PBMC from 10 different healthy donors are shown in Figure 6a. rec(GMCSF) induced a significantly higher IFN- $\alpha$ response in comparison to rec $(-)$. Also, rec(GM-CSF)-infected MCF-7 vaccine cells induced an IFN- $\alpha$ response in PBMC, which was significantly higher than that induced by $\operatorname{rec}(-)-$ infected vaccine cells (Figure 6b). PBMC control cultures or those stimulated with uninfected vaccine cells (data not shown) were negative. True infection of tumor cells by the rec viruses was important since UV inactivated virus was much less efficient (data not shown).

The increased IFN- $\alpha$ response of PBMC to rec(GM$\mathrm{CSF}$ ) virus could theoretically be due to a combined effect of GM-CSF and infection by NDV. The results from experiments testing this possibility are shown in Figure 6c. When recombinant GM-CSF protein (recGM-CSF) was added to rec $(-)$ virus or $\mathrm{V}(\mathrm{rec}(-))$ vaccine to stimulate PBMC, we did not observe an increased IFN$\alpha$ response. Even higher amounts of GM-CSF did not work while rec(GM-CSF) virus was effective over a broad dose range (data not shown). Thus, rec(GM-CSF) is a new vector with an added value in comparison to rec $(-)$ virus and also in comparison to GM-CSF protein.

To find out which cell types in PBMC are responsible for the increased IFN- $\alpha$ response seen with $\operatorname{rec}(\mathrm{GM}-\mathrm{CSF})$, we tested purified monocytes, which were positively

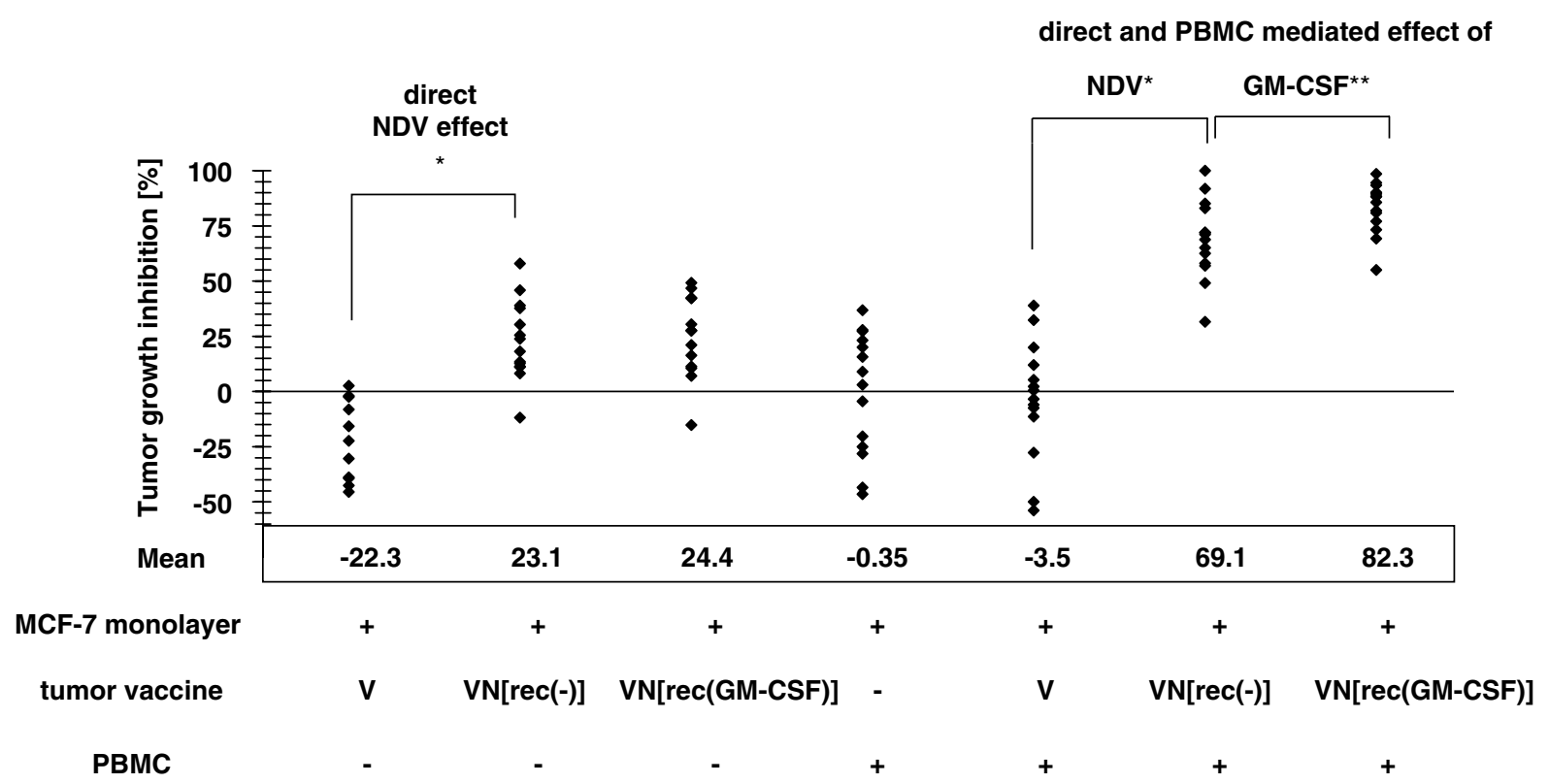

Figure 5 Effect of GM-CSF producing tumor vaccine in a tumor neutralization assay. To produce an MCF-7 monolayer, 48-well plates were seeded with 14000 live MCF-7 cells and incubated for $4 \mathrm{~h}$ to enable the adherence to the bottom. Then wells of different experimental groups received 24000 irradiated MCF-7 vaccine cells (V) or vaccine cells infected by rec(-) (VN[rec(-)]) or by rec(GM-CSF (VN[rec(GM-CSF)]) and 96000 fresh human PBMC as effector cells ( $400 \mu$ volume total). Since the effector activity of PBMC is variable depending on the donor, we performed separate experiments with PBMC from 14 different healthy donors. Data represent the mean of TGI of all donors, which was determined by triplicate measurements. In addition, the mean is shown under the respective group. A Student's $t$-test revealed the significance of the differences between certain groups. ${ }^{*} P<10^{-5},{ }^{* *} P<0.004$. TGI, tumor growth inhibition. 


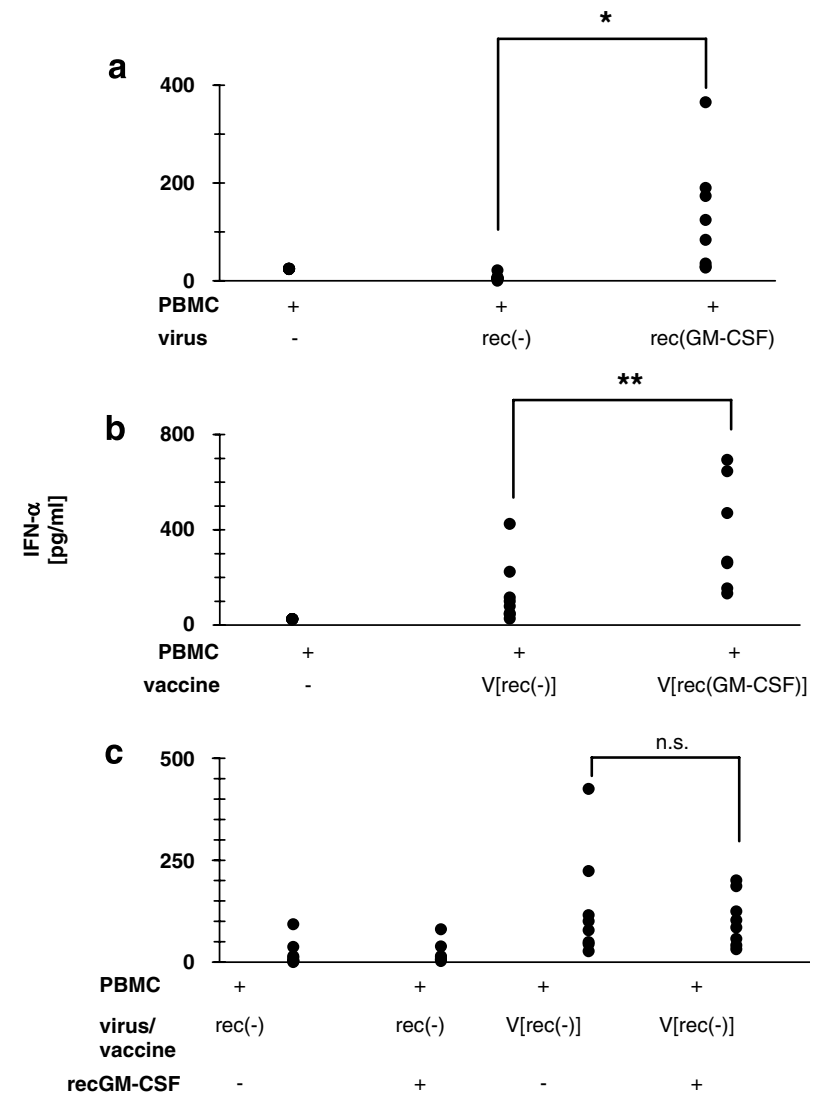

Figure 6 IFN- $\alpha$ response of PBMC from normal donors. Stimulation was performed (a) with the recombinant viruses rec(-) and rec(GM-CSF); (b) with tumor vaccine cells infected with these two recombinant viruses or (c) with recombinant GM-CSF protein in addition to rec(-) or to the tumor vaccine infected with rec(-). (a) In a 24-well plate, $5 \times 10^{4}$ PBMCs from eight healthy donors were co-incubated or not with the two recombinant viruses rec $(-)$ and rec(GM-CSF) at a concentration of $1 \mathrm{HU}$ per $10^{7} \mathrm{PBMC}$ and in a final volume of $500 \mu \mathrm{l}$. Results show the IFN- $\alpha$ expression in the supernatant $24 \mathrm{~h}$ later as tested by ELISA $\left({ }^{*} P=0,0096\right)$. (b) The same PBMCs as in (a) $\left(5 \times 10^{5}\right.$ per well of a 24 -well plate $)$ were stimulated with $4.8 \times 10^{4}$ vaccine cells pre-infected with rec(-) or rec(GM-CSF) (10 HU per $10^{7}$ vaccine cells) in a total volume of $500 \mu \mathrm{l}$. After $24 \mathrm{~h}$, the supernatants of these co-cultures were collected and tested for IFN- $\alpha$ by ELISA. The addition of uninfected MCF-7 vaccine cells to the different PBMCs did not lead to induction of IFN- $\alpha$ (data not shown) $(* * P=0.014)$. (c) Recombinant GM-CSF protein was given at a final concentration of $20 \mathrm{ng} \mathrm{ml}^{-1}$ onto PBMCs $\left(5 \times 10^{5}\right.$ cells per well) of the different donors in addition to rec(-) present at a concentration of $10 \mathrm{HU}$ per $10^{7} \mathrm{PBMC}$ or to MCF-7 vaccine cells pre-infected with rec(-) as in (b) in a final volume of $500 \mathrm{ml}$. After $24 \mathrm{~h}$, the supernatants were tested for IFN- $\alpha$ by ELISA. NS, not significant. IFN- $\alpha$, interferon- $\alpha$; GM-CSF, granulocyte/macrophage colony-stimulating factor; PBMC, peripheral blood mononuclear cells.

selected with CD14 magnetic beads and PBMC depleted of CD14-positive monocytes. As shown in Figures 7a and $b$ both cell fractions responded to rec(GM-CSF) stimulation. We further fractionated CD14- ${ }^{-}$PBMC with BDCA-4 and BDCA-2 monoclonal antibody (mAb) staining and cell sorting and found that only the BDCA $-4^{+}$BDCA $-2^{+}$ double positive fraction of PDCs responded to stimulation with NDV. This response could be blocked by BDCA-2-specific mAb, an antibody that is known to block the IFN- $\alpha$ response of PDCs, ${ }^{19}$ while a respective isotype control did not interfere with the response to
rec(GM-CSF)-purified PDC (data not shown). Similar results were obtained with $\mathrm{CD} 14^{-}$PBMC (Figure $7 \mathrm{~b}-\mathrm{d}$ ), suggesting that PDCs are responsible for the response of this fraction. We thus conclude that $\operatorname{rec}(\mathrm{GM}-\mathrm{CSF})$ stimulates two sub-populations of PBMC for IFN- $\alpha$ production, namely $\mathrm{CD} 14^{+}$monocytes and $\mathrm{CD} 14^{-}$ BDCA-2+ PDCs.

\section{Discussion}

The aim of the study was to further improve the tumor vaccine ATV-NDV, which is elaborated by infection of irradiated tumor cells with the lentogenic strain Ulster of NDV and showed promising results in clinical studies. $13,14,16$ To this end, we inserted an additional gene coding for GM-CSF within the viral genome in such a way that viral infection of tumor cells leads to secretion of GMCSF. We show here that the insertion of this additional therapeutic gene significantly increases the immune stimulatory properties of the virus and the antitumor effects of a respective tumor vaccine in a tumor neutralization assay in vitro.

Using NDV as vector for tumor gene therapy offers several advantages over other viral expression systems: (1) high safety profile. This is due to the fact that NDV is an avian RNA virus. Viral infection and replication occur exclusively in the cytoplasm. No viral DNA is generated and no genetic recombination can occur with host cell DNA; (2) tumor cell infection efficiency. All the tumor cell lines tested in our laboratory were easy to infect and showed a high permissivity with $80 \%$ of the cells being infected. Viral replication is independent of cell proliferation and proceeds efficiently in tumor cells inactivated by $\gamma$-irradiation. ${ }^{20}$ Already after $24 \mathrm{~h}$, the cells are fully infected by the virus. No selection for tumor cell transfectants is necessary as is the case with retroviral vectors for which technical hurdles have been described. ${ }^{21}$ In fact the efficiency of the retroviral vector approach was so low that from 116 malignant gliomas only three transfectants were successfully established and could be applied to the patients. ${ }^{21}$ For comparison, in our glioblastoma study, ${ }_{13}^{13}$ the efficiency of ATV-NDV tumor vaccine production (autologous cell cultures plus virus infection) was $90 \%$.

Since NDV is a negative strand RNA virus, reverse genetics technology had to be employed for the elaboration of recombinant NDV. The rescue system has been established with the strain La Sota. ${ }^{15}$ Cloned La Sota virus NDFL was found to have similar properties as Ulster. The La Sota strain has already been shown to be safe in a clinical trial with stage I-IV malignant tumors of the digestive tract. ${ }^{22}$ Other data obtained by us (not shown here) revealed that NDFL (i) shows tumor selective replication as observed for NDV Ulster, ${ }^{23}$ (ii) has a monocyclic replication cycle in tumor cells and (iii) produces noninfectious progeny virus similar to NDV Ulster. ${ }^{21}$

The only difference between the two virus strains was that NDFL $(\operatorname{rec}(-))$ had about three times higher cytotoxic effects on tumor cells as revealed by the Nicoletti assay. Such increased tumor cytotoxic effect may lead to an improvement of the immune response through uptake of apoptotic bodies and cross-presentation of tumor-associated antigens via host DCs. ${ }^{24}$ Secretion of GM-CSF by infected tumor cells should activate 


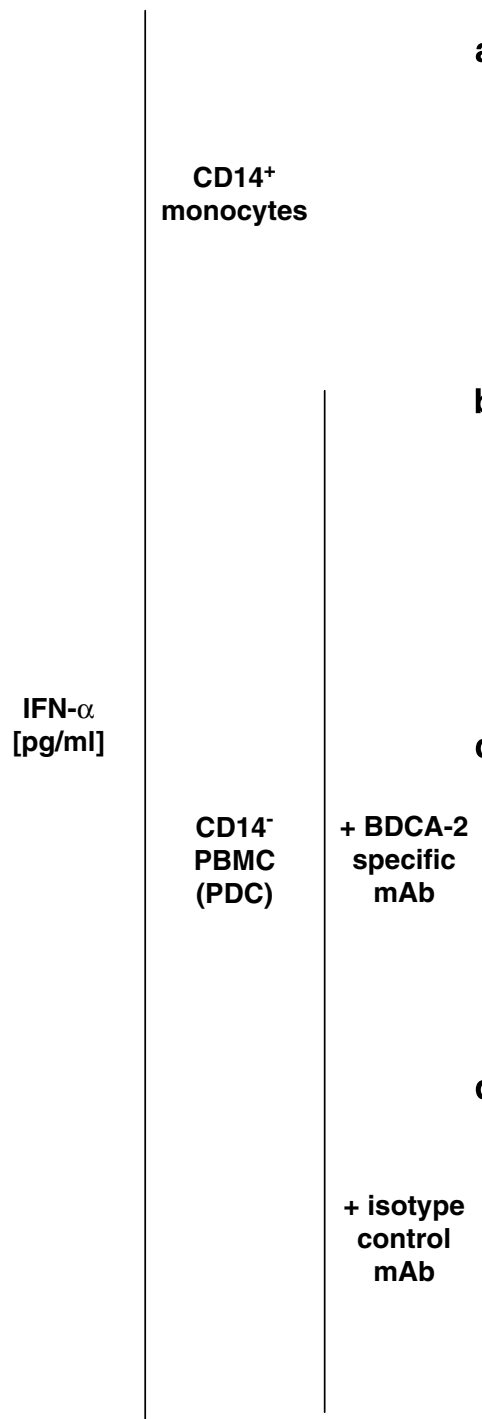

a 400

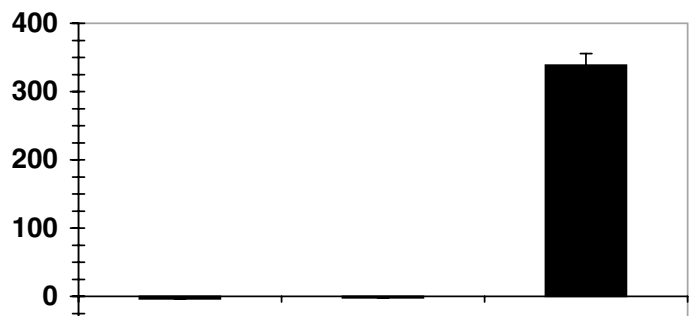

b

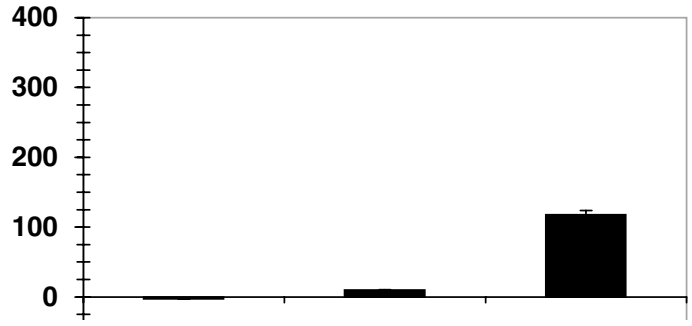

C

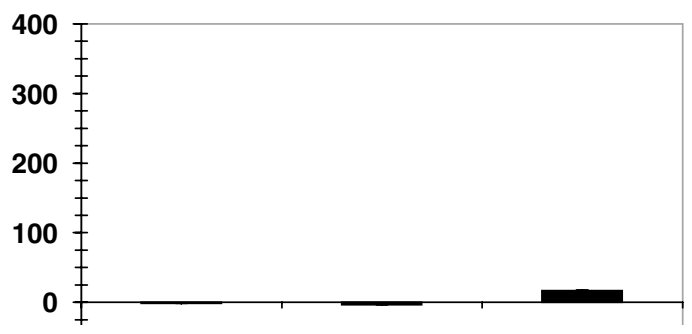

d 400

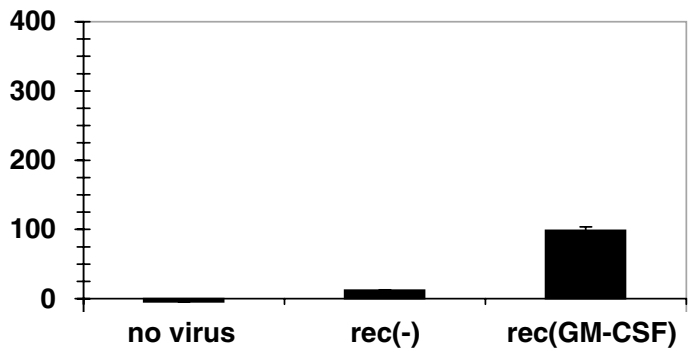

Figure 7 IFN- $\alpha$ response to rec(GM-CSF) virus by monocytes and plasmacytoid DCs. Monocytes were purified or depleted from PBMC of a healthy donor using anti-CD14-specific $\mathrm{mAb}$ and magnetic beads. Staining and flow cytometry analysis confirmed a high purity of the obtained monocytes fraction. A $5 \mathrm{HU}$ of rec(-) or rec(GM-CSF) (or no virus as control) was added to $5 \times 10^{5}$ cells in $24-$ well plates (500 $\mu \mathrm{l}$ volume per well) to the monocytes (a) or to the remaining CD14 depleted PBMC (b). $\mathbf{c}$ and $\mathbf{d}$ additionally contained anti-BDCA-2 mAb or isotype control $\mathrm{mAb}$, respectively $\left(3 \mu \mathrm{g} \mathrm{ml}^{-1}\right)$. After 1 day of incubation, the level of IFN- $\alpha$ was determined by ELISA. IFN- $\alpha$, interferon- $\alpha$; GM-CSF, granulocyte/macrophage colony-stimulating factor; PBMC, peripheral blood mononuclear cell; ELISA, enzyme-linked immunosorbent assay; mAb, monoclonal antibody.

and attract antigen-presenting cells, thereby inducing a tumor-specific cellular immune response. The GM-CSF of the vaccine produced with rec(GM-CSF) could further stimulate this process by recruiting more DCs to the site of vaccination and by improving cross-presentation via IFN- $\alpha$ and by upregulation of costimulatory molecules on DCs. This is a critical first step in the induction of an optimal immune response to any immunotherapy product at the injection site. ${ }^{25,26}$

GM-CSF appears to be a very attractive therapeutic gene because it was the most potent among multiple cytokines and growth factors transduced into a syngeneic, non-immunogenic, B16 melanoma tumor cell vaccine. ${ }^{26,27}$ GM-CSF was shown to recruit and maturate DCs, macrophages and neutrophils. ${ }^{26}$ It showed already interesting effects in vaccination studies ${ }^{25,27-29}$ and also some objective clinical regression of metastatic breast cancer. ${ }^{30}$

In this study, two positions of insertion for the GMCSF therapeutic gene were tested. The position close to the $3^{\prime}$ proximal end showed a higher recombinant protein expression than the other one. The NDV RNAdependent RNA polymerase initiates its binding to the RNA template at the leader sequence close to the $3^{\prime}$ end of the genomic RNA. It performs the transcription of the six different genes within the viral genome in a discontinuous manner by starting the transcription of each gene at the Gene Start (GS) sequence and ending it at the Gene End (GE) sequence. This leads to the generation of a gradient of mRNAs from the $3^{\prime}$ end to 
the $5^{\prime}$ end and a corresponding gradient in the amounts of the different proteins. This explains the faster (within the first $24 \mathrm{~h}$ ) and stronger expression of the therapeutic gene product when testing the virus with the GM-CSF gene inserted in front of the NP gene. Furthermore, irradiation of the tumor cells before infection with rec(GM-CSF) did not interfere with the level of protein produced.

GM-CSF expressed by rec(GM-CSF)-infected tumor cells was stable up to 30 days and it was biologically active. The cytokine served as a growth factor for GMCSF-dependent TF-1 cells and murine bone marrow cells and caused maturation of DCs. GM-CSF was not only produced by tumor cells but also by PBMC upon infection with rec(GM-CSF) (data not shown). We reported before that NDV can infect PBMC and produce positive strand viral $\mathrm{RNA}^{23}$ but the antiviral response of $\mathrm{PBMC}^{23}$ prevents further viral replication and associated cell death.

To investigate the antitumoral activity of PBMC upon stimulation with tumor vaccine cells infected by rec viruses, we used a previously established TNA, which allows testing for bystander antitumor activity. We demonstrate that bystander antitumor activity can be increased significantly when using rec(GM-CSF) virus in comparison to $\operatorname{rec}(-)$ virus for the elaboration of the tumor vaccine. These TNA experiments were performed with 14 different PBMC donors because of the great variability in the activity of PBMC from different donors. The findings corroborate results from other tumor vaccine systems in which either vaccinia virus, ${ }^{31}$ retrovirus $^{30}$ or HSV-1 amplicons ${ }^{32}$ were used as vectors to transfer the GM-CSF gene into tumor cells.

An unexpected but encouraging finding was that PBMC responded to addition of $\mathrm{rec}(\mathrm{GM}-\mathrm{CSF})$ with a strong production of IFN- $\alpha$. This response was significantly higher than the IFN- $\alpha$ response to either rec (-) virus or to recombinant GM-CSF. There seems to be a synergistic effect in this response between virus infection and production of GM-CSF thus providing rec(GM-CSF) with an added value in comparison to the recombinant protein. Addition of irradiated MCF-7 vaccine cells infected with rec (GM-CSF) to PBMC also showed a significantly enhanced IFN- $\alpha$ response. IFN- $\alpha$ has a central importance not only as an antiviral agent but also for innate and adaptive immune responses. ${ }^{19,33}$ It may thus also be involved in the observed increased bystander antitumor effects.

Recent preclinical studies have demonstrated further enhancement of antitumor immunity when a tumor vaccine secreting GM-CSF is combined with (i) blockade of CTLA- $4{ }^{34}$ (ii) blockade of vascular endothelial growth factor $^{35}$ or (iii) immunomodulatory doses and schedules of certain chemotherapeutic agents. ${ }^{36}$ Also a combination of IFN- $\alpha$ and GM-CSF secreting tumor vaccine was shown to significantly enhance the potency of the immunotherapeutic effect. ${ }^{37}$ The expression of the $\mathrm{HN}$ protein of NDV at the cell surface of the ATV-NDV tumor vaccine $^{5}$ as well as the replication of NDV within these cells may be of central importance for the induction of IFN- $\alpha$ at the vaccination site and consequently for the observed antitumor response in clinical studies based on NDV tumor vaccine. ${ }^{16}$

Here, we show that a tumor vaccine obtained by irradiation and infection with $\operatorname{rec}(G M-C S F)$ induces a stronger IFN- $\alpha$ response in human monocytes and PDCs than a vaccine infected with the virus without incorporated foreign gene. Interestingly, $\operatorname{rec}(\mathrm{GM}-\mathrm{CSF})$ virus was found to exert immunostimulatory effects; which were superior to a mixture of rec $(-)$ virus and GM-CSF protein. Earlier experiments had revealed that the type I IFN response leads to upregulation of TRAIL on monocytes and to monocyte mediated antitumor cytotoxicity. ${ }^{38}$ Soluble TRAIL-Fc molecules were able to inhibit such cytotoxicity ${ }^{38}$ and they also inhibited partially (about 50\%) the effects measured by the TNA test (data not shown). Preliminary tests also revealed that in a TNA with rec(GM-CSF)-infected vaccine, monocytes show increased TRAIL expression, DCs show increased expression of CD80 and CD86 costimulatory molecules and tumor cells from the monolayer show increased expression of Apo 2.7, a marker for early apoptotic events (M Janke, unpublished results). Through the stronger activation of innate immune effects, we expect that a tumor vaccine infected with rec(GM-CSF) will also induce a stronger adaptive immune response because IFN- $\alpha$ provides a link between both immunity systems. ${ }^{39,40}$

In summary, this study shows that the immune stimulatory and antitumoral properties of NDV can be further augmented by incorporation of a foreign gene. More specifically our data suggest that rec(GM-CSF), a recombinant NDV that produces GM-CSF and induces a strong IFN- $\alpha$ response represents a promising new viral vector for human tumor immunogene therapy.

\section{Materials and methods}

\section{Antibodies and chemicals}

For flow cytometry analysis, the following mAbs against mouse antigens were used at 1:100 dilution: CD11c-FITC, H2D ${ }^{\mathrm{d}}$-PE (Pharmingen, Hamburg, Germany). Mouse anti-HN mAb (HN.B mAb, IgG2a) and mouse anti-F $\mathrm{mAb}$ lcii (IgG1) were kindly provided by Dr Iorio (Department of Molecular Genetics and Microbiology, University of Massachusetts, Medical School, Worcester, MA, USA) and used at $1 \mu \mathrm{g} / 5 \times 10^{5}$ cells. These two antibodies were used to detect NDV viral antigens on host cell surfaces. To detect the unconjugated antiviral antibodies, cells were incubated with secondary $\mathrm{mAb}$ goat $\mathrm{F}(\mathrm{ab})_{2}$ anti-mouse Ig-RPE (1:50) obtained from Southern Biotechnology Associates Inc. (Birmingham, AL, USA). Propidium iodide was purchased from Sigma (Deisenhofen, Germany).

For blocking experiments, we used unlabeled antihuman BDCA-2 (IgG1) mAb at $3 \mu \mathrm{g} \mathrm{ml}^{-1}$ (Miltenyi, Bergisch Gladbach, Germany). The isotype control HD20 (IgG1) was a gift from Dr Gerd Moldenauer (DKFZ, Heidelberg, Germany) and was used at identical concentrations. ELISA experiments for the detection of human GM-CSF (Pharmingen, Hamburg, Germany) and human IFN- $\alpha$ (Bender Medsystems, San Bruno, CA, USA) were performed in accordance to the manufacturer's guidelines. Recombinant GM-CSF protein (commercial trade name: Leukine Sargramostin) was purchased from Berlex Laboratories Inc. (Richmond, VA, USA).

MTS Cell Titer 96 Aqueous solution was purchased from Promega (Mannheim, Germany). 


\section{Cell lines and culture}

All tumor cells were obtained from the Tumorbank DKFZ (Heidelberg, Germany) except the MCF-10A human breast hyperplasia-derived cell line, which was purchased from ATCC (Manassas, VA, USA).

The human Jurkat cell line was grown in RPMI-1640 medium supplemented with $10 \%$ inactivated fetal calf serum (FCS), $2 \mathrm{mM}$ L-glutamine, $10 \mathrm{mM}$ HEPES, $100 \mathrm{U} \mathrm{ml}^{-1}$ penicillin and $100 \mu \mathrm{g} \mathrm{ml}^{-1}$ streptomycin. The human breast carcinoma cell line MCF-7 and the human colon-adenocarcinoma cell line HT29 were maintained in Dulbecco's modified Eagle's medium containing $10 \%$ inactivated FCS, $2 \mathrm{mM}$ L-glutamine, $10 \mathrm{mM}$ HEPES, $100 \mathrm{U} \mathrm{ml}^{-1}$ penicillin and $100 \mu \mathrm{g} \mathrm{ml}^{-1}$ streptomycin.

The non-tumorigenic but immortalized human breast epithelial cell line MCF-10A was cultured in Dulbecco's modified Eagle's medium with 5\% horse serum, $10 \mathrm{mM}$ HEPES, $100 \mathrm{U} \mathrm{ml}^{-1}$ penicillin, $100 \mu \mathrm{g} \mathrm{ml}^{-1}$ streptomycin, $500 \mathrm{ng} \mathrm{ml}^{-1}$ hydrocortisone, $0.01 \mathrm{mg} \mathrm{ml}^{-1}$ insulin, $20 \mathrm{ng} \mathrm{ml}^{-1}$ epidermal growth factor and $100 \mathrm{ng} \mathrm{ml}^{-1}$ choleratoxin. TF-1 is a human premyeloid cell line, which was originally established by Dr Kitamura from a patient with erythroleukemia. This cell line, whose growth is dependent on GM-CSF was purchased from ATCC (cat. no. CRL-2003). The myeloma cell line Ag8653 expressing mouse recombinant GM-CSF was cultured to produce mouse GM-CSF. All these cells were grown in RPMI-1640 medium with $10 \%$ FCS, $100 \mathrm{U} \mathrm{ml}^{-1}$ penicillin, $100 \mu \mathrm{g} \mathrm{ml}^{-1}$ streptomycin, $10 \mathrm{mM}$ HEPES, $1 \mathrm{mM}$ sodium pyruvate, $2.5 \mathrm{mg} \mathrm{ml}^{-1}$ glucose and $25 \mu \mathrm{g} \mathrm{ml}^{-1}$ GM-CSF.

All reagents for cell culture were purchased from Gibco Life Technologies (Karlsruhe, Germany) except FCS, which was from Biochrom (Krefeld, Germany) and the horse serum, hydrocortisone, insulin, epidermal growth factor and choleratoxin were purchased from Sigma (Deisenhofen, Germany). GM-CSF used as standard was obtained from Promocell (Heidelberg, Germany). All cell lines were incubated at $37^{\circ} \mathrm{C}$ in a humidified atmosphere of $5 \% \mathrm{CO}_{2}$.

\section{Plasmids and virus}

The plasmid called pNDFL, which contains the six genes of the negative-stranded RNA genome of NDV strain La Sota in the order $3^{\prime}$-NP-P-M-F-HN-L-5' has been described by Peeters et al. ${ }^{15}$ The plasmid pCD-hGM-CSF encoding the human GM-CSF gene was purchased from ATCC (cat. no. 57594).

NDV-Ulster 2C was obtained in 1984 from Dr PH Russel (University London, UK).

All the viruses (recombinant or not) were propagated in embryonated chicken eggs, harvested from the allantoic fluid, purified by ultracentrifugation and quantified by hemagglutination as described previously. ${ }^{2}$ In some experiments, the virus was inactivated with UV light for $5 \mathrm{~min}\left(254 \mathrm{~nm}, 2 \mathrm{~mW} \mathrm{~cm}^{-2}, 7 \mathrm{~cm}\right.$ distance).

\section{Purification of blood-derived cells}

Human PBMCs were isolated from buffy coat of healthy donors by Ficoll-Paque (Amersham Pharmacia Biotech, Freiburg, Germany) density gradient centrifugation.

In some assays, PBMCs were depleted from monocytes by using magnetic beads coated with CD14-specific mAbs and MACS columns (both Miltenyi, Bergisch
Gladbach, Germany). We also tested the positively selected $\mathrm{CD} 14^{+}$monocytes.

\section{Production of virus-infected tumor vaccine stimulator cells}

As stimulator cells for mixed lymphocyte-tumor cell cultures (MLTC) and the TNA, we used MCF-7 breast carcinoma cells that were inactivated with $200 \mathrm{~Gy}$ irradiation via a ${ }^{137} \mathrm{C}$ s source (Gammacell 1000, Atomic Energy of Canada, Chalk River, Canada) and then infected with the respective NDV strain $(100 \mathrm{HU}$ per $10^{7}$ cells per $\mathrm{ml}$ ) as described. ${ }^{2}$

\section{Flow cytometry}

A total of $5 \times 10^{5}$ cells were used per sample. All antibodies were diluted in flow cytometry buffer (PBS containing 5\% FCS and $0.1 \% \mathrm{NaN}_{3}$ ) as described in the antibody section. Cells were incubated with a primary (un-) conjugated antibody for $20 \mathrm{~min}$ on ice in the dark. Subsequently cells were washed two times with flow cytometry buffer and, if necessary incubated with a conjugated secondary antibody for $20 \mathrm{~min}$ on ice in the dark. Then the cells were washed two times, adjusted to a volume of $100 \mu$ l and analyzed in a FACS Calibur flow cytometer (Becton \& Dickinson, Heidelberg, Germany). All flow cytometry data were analyzed with CELLQuest Pro software (Becton \& Dickinson, Heidelberg, Germany).

\section{Apoptosis assays}

For determination of late apoptotic cells a Nicoletti staining was performed. Briefly, $5 \times 10^{5}$ cells were washed in PBS, incubated with $250 \mu \mathrm{l}$ Nicoletti solution $\left(0.05 \mathrm{mg} \mathrm{ml}^{-1}\right.$ propidium iodide, $0.1 \%$ sodium citrate and $0.1 \%$ Triton $\mathrm{X}-100$ in PBS) for at least $48 \mathrm{~h}$ at $4{ }^{\circ} \mathrm{C}$ in the dark and then analyzed by flow cytometry.

\section{Tumor neutralization assay}

The assay was performed in 48-well round-bottom plates. A total of $1.4 \times 10^{4}$ live MCF-7 tumor cells in Dulbecco's modified Eagle's medium with 5\% FCS were added to each well and incubated for $4 \mathrm{~h}$ at $37^{\circ} \mathrm{C}$ to adhere.

Subsequently, $9.6 \times 10^{4}$ freshly isolated non-activated PBMC from normal healthy donors were added to the respective wells. A total of $2.4 \times 10^{4}$ stimulator cells per well were prepared by irradiation and virus infection as indicated. The total volume per well was $400 \mu \mathrm{l}$. The microtiter plates were then wrapped in cling film to prevent evaporation of medium and incubated in a $\mathrm{CO}_{2}$ incubator at $37^{\circ} \mathrm{C}$. The time of incubation depended on the time for confluence of the tumor cell monolayer in control wells without stimulator or effector cells. All experimental wells were performed in triplicates. At the end of the assay, supernatants were removed by suction and the plates were carefully washed twice with RPMI containing 5\% FCS to remove effector and stimulator cells. Then $200 \mu \mathrm{l}$ of RPMI with $5 \%$ FCS and $40 \mu \mathrm{l}$ MTS solution (3-(4,5-dimethythiazol-2-yl)-5-(3-carboxymethoxyphenyl)-2-(4-sulfophenyl)-2H-tetrazolium, MTS) were added per well and incubated for $20-40 \mathrm{~min}$ at $37^{\circ} \mathrm{C}$ in the dark. After color switch, the reaction was stopped by transfer of each well content to a 96-well plate containing $20 \mu 110 \%$ SDS per well. The plates were then evaluated 
in an ELISA reader at $490 \mathrm{~nm}$. The background was taken from control wells containing only medium and MTS solution. The result was displayed as percent tumor growth inhibition related to an untreated monolayer (positive control) calculated according to:

$$
\begin{aligned}
& 1-\left(\frac{\mathrm{A}_{490} \text { experimental well }-\mathrm{A}_{490} \text { background }}{\mathrm{A}_{490} \text { positive control }-\mathrm{A}_{490} \text { background }}\right) \times 100 \\
& =\% \text { growth inhibition }
\end{aligned}
$$

\section{Cytokine-dependent proliferation assay}

We used GM-CSF-dependent TF-1 cells to analyze the biological activity of the expressed integrated cytokine genes released during viral tumor cell infection.

One day prior to the assay, the indicator cells were transferred to cytokine-free medium. For the assay, the cells were then harvested, washed three times with cytokine free medium and adjusted to a cell number of $2 \times 10^{5} \mathrm{ml}^{-1}$. A $50 \mu \mathrm{l}$ of cell suspension was added to a 96-well plate, which contained serial 1:4 dilutions of the supernatants of infected tumor cells. The assay was performed in duplicates for each dilution step. After 48-72 $\mathrm{h}$ at $37{ }^{\circ} \mathrm{C} 1 \mu \mathrm{Ci}{ }^{3} \mathrm{H}$-thymidine in $50 \mu \mathrm{l} \mathrm{RPMI}$ with $5 \%$ FCS was added to each well of the plate, which then was incubated for additional $4 \mathrm{~h}$ at $37^{\circ} \mathrm{C}$. By using a micro cell harvester the radioactive DNA was transferred onto a fiberglass mat, which was analyzed in a liquid scintillation counter (Perkin Elmer Wallac, Freiburg, Germany) for thymidine incorporation.

\section{References}

1 Lorence RM, Pecora AL, Major PP, Hotte SJ, Laurie SA, Roberts MS et al. Overview of phase I studies of intravenous administration of PV701, an oncolytic virus. Curr Opin Mol Ther 2003; 5: 618-624.

2 Schirrmacher V, Haas C, Bonifer R, Ahlert T, Gerhards R, Ertel C. Human tumor cell modification by virus infection: an efficient and safe way to produce cancer vaccine with pleiotropic immune stimulatory properties when using Newcastle Disease Virus. Gene Therapy 1999; 6: 63-73.

3 Sinkovics JG, Horvath JC. Newcastle Disease Virus (NDV): brief history of its oncolytic strains. J Clin Virol 2000; 16: 1-15.

4 Gallucci S, Matzinger P. Danger signals: SOS to the immune system. Curr Opin Immunol 2001; 13: 114-119.

5 Zeng J, Fournier P, Schirrmacher V. Induction of interferon $\alpha$ and tumor necrosis factor-related apoptosis-inducing blood mononuclear cells by hemagglutinin-neuraminidase but not $\mathrm{F}$ protein of Newcastle Disease Virus. Virology 2002; 297: 19-30.

6 Fournier P, Zeng J, Schirrmacher V. Two ways to induce innate immune responses in human PBMCs: paracrine stimulation of IFN- $\alpha$ responses by viral protein or dsRNA. Int J Oncol 2003; 23: 673-680.

7 Kato H, Sato S, Yoneyama M, Yamamoto M, Uematsu S, Akira S et al. Cell type-specific involvement of RIG-I in antiviral response. Immunity 2005; 23: 19-28.

8 Clemens MJ, Elia A. The double-stranded RNA-dependent protein kinase PKR: structure and function. J Interferon Cytokine Res 1997; 17: 503-524.

9 Akira S, Takeda K. Toll-like receptor signalling. Nat Rev Immunol 2004; 4: 499-511.

10 Heicappell R, Schirrmacher V, von Hoegen P, Ahlert T, Appelhans $B$. Prevention of metastatic spread by postoperative immunotherapy with virally modified autologous tumor cells. I: parameters for optimal therapeutic effects. Int J Cancer 1986; 37: 569.
11 Schirrmacher V, Heicappell R. Prevention of metastatic spread by postoperative immunotherapy with virally modified autologous tumor cells. II: Establishment of specific systemic anti tumor immunity. Clin Exptl Met 1987; 5: 147-156.

12 Washburn B, Schirrmacher V. Human tumor cell infection by Newcastle Disease Virus leads to upregulation of HLA and cell adhesion molecules and to induction of interferons, chemokines and finally apoptosis. Int J Oncol 2002; 21: 85-93.

13 Steiner HH, Bonsanto MM, Beckhove P, Brysch M, Geletneky K, Ahmadi $\mathrm{R}$ et al. Anti-tumor vaccination of patiens with glioblastoma multiforme in a case-control study: feasibility, safety and clinical benefit. J Clin Oncol 2004; 22: 4272-4281.

14 Karcher J, Dyckhoff G, Beckhove P, Reisser C, Brysch M, Zionta $Y$ et al. Anti-tumor vaccination with HNSCC with autologous virus-modified tumor cells. Cancer res 2004; 64: 8057-8061.

15 Peeters BP, de Leeuw OS, Koch G, Gielkens AL. Rescue of Newcastle Disease Virus from cloned cDNA: evidence that cleavability of the fusion protein is a major determinant for virulence. J Virol 1999; 73: 5001-5009.

16 Schirrmacher V. Clinical trials of antitumor vaccination with an autologous tumor cell vaccine modified by virus infection: Improvement of patient survival based on improved anti-tumor immune memory. Cancer Immunol Immunother 2005; 54: 587-598.

17 Zhao H, Peeters BPH. Recombinant Newcastle disease virus as a viral vector: effect of genomic location of foreign gene on gene expression and virus replication. J Gen Virol 2003; 84: 781-788.

18 Haas C, Lulei M, Fournier P, Arnold A, Schirrmacher V. A tumor vaccine containing anti-CD3 and anti-CD28 bispecific antibodies triggers strong and durable anti-tumor activity in human lymphocytes. Int J Cancer 2005; 118: 658-667.

19 Dzionek A, Sohma Y, Nagafune J, Cella M, Colonna M, Facchetti F et al. BDCA-2, a novel plasmacytoid dendritic cell-specific type II C-type lectin, mediates antigen capture and is a potent inhibitor of interferon alpha/beta induction. J Exp Med 2001; 194: 1823-1834.

20 Schirrmacher V, Haas C, Bonifer R, Ertel C. Virus potentiation of tumor vaccine $\mathrm{T}$-cell stimulatory capacity requires cell surface binding but not infection. Clin Cancer Res 1997; 3: 1135-1148.

21 Parney IF, Chang LJ, Farr-Jones MA, Hao C, Smylie M, Petruk KC. Technical hurdles in a pilot clinical trial of combined B7-2 and GM-CSF immunogene therapy for glioblastomas and melanomas. J Neurooncol 2006; 78: 71-80.

22 Liang W, Wang H, Sun TM, Yao WQ, Chen LL, Jin Y et al. Application of autologous tumor cell vaccine and NDV vaccine in treatment of tumors of digestive tract. World J Gastroenterol 2003; 9: 495-498.

23 Fiola C, Peeters B, Fournier P, Arnold A, Bucur M, Schirrmacher V. Tumor selective replication of Newcastle Disease Virus: Association with defects of tumor cells in anti-viral defence. Int J Cancer 2006; 119: 328-338.

24 Scheffer SR, Nave H, Korangy F, Schlote K, Pabst R, Jaffee EM et al. Apoptotic, but not necrotic, tumor cell vaccines induce a potent immune response in vivo. Int J Cancer 2003; 103: 205-211.

25 Soiffer R, Hodi FS, Haluska F, Jung K, Gillessen S, Singer S et al. Vaccination with irradiated, autologous melanoma cells engineered to secrete granulocyte-macrophage colony-stimulating factor by adenoviral-mediated gene transfer augments antitumor immunity in patients with metastatic melanoma. J Clin Oncol 2003; 21: 3343-3350.

26 Jaffee EM, Lazenby A, Meurer J, Marshall F, Hauda KM, Counts $\mathrm{C}$ et al. Use of murine models of cytokine-secreting tumor vaccines to study feasibility and toxicity issues critical to designing clinical trials. J Immunother Emphasis Tumor Immunol 1995; 18: 1-9.

27 Dranoff G, Jaffee E, Lazenby A, Golumbek P, Pardoll D, Mulligan RC et al. Vaccination with irradiated tumor cells engineered to secrete murine granulocyte-macrophage 
colony-stimulating factor stimulates potent, specific, and longlasting anti-tumor immunity. Proc Natl Acad Sci USA 1993; 90: 3539-3543.

28 Driessens G, Hamdane M, Cool V, Velu T, Bruyns C. Highly successful therapeutic vaccination combining dendritic cells and tumor cells secreting granulocyte macrophage colony-stimulating factor. Cancer Res 2004; 64: 8435-8442.

29 Luiten RM, Kueter EW, Mooi W, Gallee MP, Rankin EM, Gerritsen WR et al. Immunogenicity, including vitiligo, and feasibility of vaccination with autologous GM-CSF-transduced tumor cells in metastatic melanoma patients. J Clin Oncol 2005; 23: 8978-8991.

30 Wiseman CL, Kharazi A. Objective clinical regression of metastatic breast cancer in disparate sites after use of wholecell vaccine genetically modified to release sargramostim. Breast J 2006; 12: 475-480.

31 Qin HX, Chatterjee SK. Construction of recombinant vaccinia virus expressing GM-CSF and its use as tumor vaccine. Gene Therapy 1996; 3: 59-66.

32 Santos K, Duke CM, Dewhurst S. Amplicons as vaccine vectors. Curr Gene Ther 2006; 6: 383-392.

33 Stetson DB, Medzhitov R. Type I interferons in host defense. Immunity 2006; 25: 373-381.

34 Hurwitz AA, Yu TF, Leach DR, Allison JP. CTLA-4 blockade synergizes with tumor-derived granulocyte-macrophage colony-stimulating factor for treatment of an experimental mammary carcinoma. Proc Natl Acad Sci USA 1998; 95: 10067-10071.

35 Li B, Lalani AS, Harding TC, Luan B, Koprivnikar K, Huan Tu G et al. Vascular endothelial growth factor blockade reduces intratumoral regulatory $t$ cells and enhances the efficacy of a GM-CSF-secreting cancer immunotherapy. Clin Cancer Res 2006; 12: 6808-6816.

36 Machiels JP, Reilly RT, Emens LA, Ercolini AM, Lei RY, Weintraub $\mathrm{D}$ et al. Cyclophosphamide, doxorubicin, and paclitaxel enhance the antitumor immune response of granulocyte/macrophagecolony stimulating factor-secreting whole-cell vaccines in HER-2/ neu tolerized mice. Cancer Res 2001; 61: 3689-3697.

37 Prell RA, Li B, Lin JM, VanRoey M, Jooss K. Administration of IFN- $\alpha$ enhances the efficacy of a granulocyte macrophage colony stimulating factor-secreting tumor cell vaccine. Cancer Res 2005; 65: 2449-2456.

38 Washburn B, Weigand MA, Grosse-Wilde A, Janke M, Stahl H, Rieser $\mathrm{E}$ et al. TNF-related apoptosis-inducing ligand mediates tumoricidal activity of human monocytes stimulated by Newcastle disease virus. J Immunol 2003; 170: 1814-1821.

39 LeBon A, Tough DF. Links between innate and adaptive immunity via type I interferon. Curr Opin Immunol 2002; 14: 432-436.

40 Tough DF. Type I interferon as a link between innate and adaptive immunity through dendritic cell stimulation. Leuk Lymphoma 2004; 45: 257-264. 